\title{
Combined obesity among adult in-patients: A study in a tertiary care hospital
}

\author{
Nandini R.C ${ }^{1}$, Sanjay T.V ${ }^{2, *}$, Thejaswini .P³ , Ramu .P. ${ }^{4}$, Channaraya $V^{5}$ \\ ${ }^{1,3,4}$ Post Graduate Student, ${ }^{2,5}$ Professor, ${ }^{1-4}$ Dept. of Community Medicine, ${ }^{5}$ Dept. of Medicine, Kempegowda Institute of Medical \\ Sciences Hospital and Research Center (KIMSH\&RC), Bangalore, Karnataka, India
}

*Corresponding Author:

Email: drsanjaytv@gmail.com

\begin{abstract}
Introduction: Obesity is one of the major risk factors for number of preventable non-communicable diseases (NCD's). In adults, the combined measure of BMI and waist circumference provides better information on obesity in either sex. This gives good opportunity to predict the risk of development of NCD's better compared to the use of individual index. In this context, present study was undertaken.

Materials and Methods: Data was collected from 228 adult in-patients in a tertiary care hospital of Bengaluru, regarding sociopersonal profile, dietary habits, physical exercise practices and co-morbidities. Anthropometric measurements such as height, weight and waist circumference were recorded and, BMI and waist circumference were combined as composite index.

Results: The proportion of combined obesity was $32.9 \%$ and family history of obesity $(\mathrm{p}=0.01$ ), history of alcohol intake $(\mathrm{p}=0.02)$, presence of two or more co-morbidities $(\mathrm{p}=0.0005)$ and hypertension with type 2 diabetes mellitus $(\mathrm{p}=0.001)$ were significantly associated with combined obesity.

Conclusions: Around one third of the adult in-patients were having combine obesity and associated with family history of obesity, alcohol intake and co-morbidities. The combined use of BMI and waist circumference is a suitable and practical index for assessment of obesity in adult in-patients.
\end{abstract}

Keywords: Combined obesity, BMI, Waist circumference, adult in-patients, Tertiary care hospital.

\section{Introduction}

Obesity is considered as a major public health concern affecting all age and socioeconomic groups both in developed and developing countries, thus WHO refers obesity as escalating global epidemic. ${ }^{1}$

Obesity is one of the major risk factors responsible for number of preventable, non-communicable diseases (NCD's) such as hypertension, diabetes mellitus, ischemic heart diseases, cancer and stroke etc. The risk of non-communicable diseases increases with increase in BMI and waist circumference. ${ }^{2}$

All over the globe, obesity has doubled between 1980 and 2014. The WHO estimates that more than 1 billion people are overweight, with 300 million meeting the criteria of obesity. ${ }^{3}$ In India, between NFHS 3 and 4 , there was a stark rise in the prevalence of obesity among adult men from $10.4 \%$ to $18 \%$ and in women from $13.9 \%$ to $19.6 \%$. $^{4}$

In the Indian adults, many studies have shown good correlation between BMI and waist circumference and their proneness for obesity related morbidity and premature mortality. ${ }^{5-6}$ In this regard, combining both BMI and waist circumference provides better information on the extent of generalized and abdominal obesity in either sex. This gives good opportunity to predict the risk of development of NCD's better compared to the use of either BMI or waist circumference alone. Extensive review of literature has shown that there is a scarcity of information on assessment of combined obesity among adults where both Body Mass Index (BMI) and waist circumference (WC) are considered.
The evidences derived from such studies provide required information to tackle generalized and central obesity simultaneously and helps to reduce the burden of obesity and related co-morbidity in near future. In this context, the present exploratory study was undertaken among adult in-patients to find out the proportion and factors associated with combined obesity based on BMI and WC in a tertiary care hospital at Bengaluru.

\section{Materials and Methods}

The present observational study was carried out in Kempegowda Institute of Medical Sciences Hospital and Research Center (KIMSH\&RC), a tertiary care hospital at Bengaluru involving the adult in-patients (>18 years to 59 years) from September to November 2016. A total of 228 study subjects were enrolled in the study by using systematic random sampling technique where every $5^{\text {th }}$ in-patient from the department of Medicine was included in the study after getting informed consent. The sample size was estimated using the formula $\mathrm{n}=4 \mathrm{pq} / \mathrm{L} 2$. The prevalence of combined obesity, "p" among adults was taken as $17.17 \%$. With precision of $5 \%$, using the above mentioned statistical formula which considers $95 \%$ confidence limits; the sample size was estimated to be $228 .{ }^{7}$

At the beginning, institutional ethics committee clearance was taken. The data was collected by an interview method, using a pre-tested semi-structured questionnaire from study subjects regarding sociopersonal profile, dietary habits, physical exercise practices and co-morbid conditions. In this study, subjects who were ambulatory and willing to participate 
were included while those who were seriously ill and having severe abnormality in speech and hearing were excluded. Anthropometric measurements such as height, weight and waist circumference were measured by following standard procedures and guidelines by trained medical professional as an investigator. The height was measured to the nearest $0.5 \mathrm{~cm}$ with stadiometer. Weight was measured to the nearest $0.5 \mathrm{~kg}$ with weighing scale. The generalised obesity was assessed by using BMI based on WHO Asia-Pacific guidelines and an International Diabetes Federation (IDF) guideline was adopted to assess central obesity (>90 $\mathrm{cm}$ for males and $>80 \mathrm{~cm}$ for females). ${ }^{8}$ The combined obesity was derived by combining both generalized and central obesity based on BMI and WC and categorizing central obesity based on sex according to BMI classification.

The data was analysed using SPSS version 21.0. The descriptive statistics such as mean and proportions and Inferential statistics such as chi-square test was used to find out the association between combined obesity and factors such as socio-personal profile, dietary habits, physical exercise practices and comorbid conditions.

\section{Results}

Out of 228 study subjects, 130 (57\%) were males and $98(43 \%)$ were females. The mean age of the study population was $36.9 \pm 13$ years, mean age of male was $37.4 \pm 13.2$ years and of female $36.1 \pm 12.7$ years. Majority belonged to age group of 41-59 years (39.5\%), most of them were Hindu by religion $(74.1 \%)$, from urban area (61.4\%), educated up to high school (31.1\%) and belonged to class-3 (according to modified B G Prasad classification) socio-economic status (53.1\%). (Table 1).

Table 1: Socio-personal profile of study subjects

*Modified BG Prasad's classification

\begin{tabular}{|c|c|c|}
\hline Variable & Category & Frequency $(\%)(n=228)$ \\
\hline Age & $41-59$ yrs & $90(39.5)$ \\
\hline Sex & Male & $130(57)$ \\
\hline Religion & Hindu & $169(74.1)$ \\
\hline Locality & Urban & $140(61.4)$ \\
\hline Education & High School & $71(31.1)$ \\
\hline Socioeconomic Status* & Class -3 & $121(53.1)$ \\
\hline
\end{tabular}

The proportion of combined obesity among the subjects (BMI $>23 \mathrm{~kg} / \mathrm{m}^{2}$ and central obesity $>90 \mathrm{cms}$ for men and $>80 \mathrm{cms}$ for women) was 75 (32.9\%) and proportion of combined obesity among males was $49(65.3 \%)$ and females 26(34.7\%) respectively. According to BMI, 33 (14.5\%) were underweight, 89 (39.4\%) were normal and $23(10.1 \%)$ were considered as overweight and $83(36.4 \%)$ were obese and totally $106(46.5 \%)$ were overweight/obese. The measurement of waist circumference shown that $99(43.4 \%)$ were considered to be centrally obese and proportion of central obesity among males were $59(59.6 \%)$ and 40 (40.4\%) among females respectingly.

The distribution of central obesity according to BMI has shown that $24(24.2 \%)$ of the study subjects under normal and below normal BMI category were having central obesity compare to only $13(13.1 \%)$ from overweight category and $43(43.5 \%)$ of the subjects having central obesity under obesity class -1 compare to $19(19.2 \%)$ from obesity class - II. (Table 2)

Table 2: Distribution of central obesity according to BMI classification (n=99)

\begin{tabular}{|l|c|c|c|}
\hline \multirow{2}{*}{ BMI classification } & \multicolumn{3}{c|}{ Central obesity } \\
\cline { 2 - 4 } & Male (\%) & Female (\%) & Total (\%) \\
\hline Underweight $\left(18.5 \mathrm{~kg} / \mathrm{m}^{2}\right)$ & - & $2(5.0)$ & $2(2)$ \\
\hline Normal $\left(18.5-22.9 \mathrm{~kg} / \mathrm{m}^{2}\right)$ & $10(16.9)$ & $12(30.0)$ & $22(22.2)$ \\
\hline Overweight $\left(23-24.9 \mathrm{~kg} / \mathrm{m}^{2}\right)$ & $8(13.6)$ & $5(12.5)$ & $13(13.1)$ \\
\hline Obesity - class $-\mathrm{I}\left(25-29.9 \mathrm{~kg} / \mathrm{m}^{2}\right)$ & $30(50.8)$ & $13(32.5)$ & $43(43.5)$ \\
\hline Obesity -class $-\mathrm{II}\left(>30 \mathrm{~kg} / \mathrm{m}^{2}\right)$ & $11(18.7)$ & $8(20.0)$ & $19(19.2)$ \\
\hline Total & $59(100.0)$ & $40(100.0)$ & $99(100)$ \\
\hline
\end{tabular}

Regarding, socio-personal profile of study subjects, statistically significant association was found between combined obesity and family history of obesity, with proportion of combined obesity being higher among subjects having family history of obesity $(40.3 \%)$ than those without family history $(25.4 \%)(\mathrm{p}=0.01)$. With regards to alcohol intake, there was a statistically significant association between combined obesity and history of alcohol intake, with proportion of combined obesity being higher among subjects having history of alcohol intake (42.3\%) than those without alcohol intake $(28 \%)$. According to co-morbidity status, there 
was a statistically significant association between combined obesity and number of co-morbidity, with proportion of combined obesity was higher among subjects having $\geq 2$ co-morbidities $(46.1 \%)$ compared to those with $<2$ co-morbidity (24\%), implying subjects with combined obesity were three times higher risk for developing $\geq 2$ co-morbidities compare to those without combined obesity $(\mathrm{OR}=2.7, \mathrm{p}=0.0005)$. There was no statistically significant association of combined obesity and age, sex, religion, locality, education, occupation, socio-economic status, type of family and history of smoking (Table 3).

Table 3: Association between Socio-personal profile of study subjects and combined obesity

\begin{tabular}{|c|c|c|c|c|c|c|c|}
\hline \multicolumn{2}{|c|}{ Variable } & \multirow{2}{*}{$\begin{array}{c}\begin{array}{c}\text { Subjects } \\
(\mathbf{n}=\mathbf{2 2 8})\end{array} \\
138\end{array}$} & \multicolumn{2}{|c|}{ Combined Obesity } & \multirow{3}{*}{$\begin{array}{c}\text { OR } \\
0.9\end{array}$} & \multirow{3}{*}{$\begin{array}{c}95 \% \text { CI } \\
0.5-1.7\end{array}$} & \multirow{3}{*}{$\begin{array}{c}\text { P-value } \\
0.9\end{array}$} \\
\hline Age (years) & $\leq 40 \mathrm{yr}$ & & $\begin{array}{c}\text { Yes } \\
45(32.6) \\
\end{array}$ & $\begin{array}{c}\text { No } \\
93(67.4)\end{array}$ & & & \\
\hline & $>40 \mathrm{yr}$ & 90 & $30(33.3)$ & $60(66.7)$ & & & \\
\hline \multirow[t]{2}{*}{ Sex } & Men & 130 & $49(37.7)$ & $81(62.3)$ & \multirow[t]{2}{*}{1.7} & \multirow[t]{2}{*}{$0.9-2.9$} & \multirow[t]{2}{*}{0.07} \\
\hline & Women & 98 & $26(26.5)$ & $72(73.5)$ & & & \\
\hline \multirow[t]{2}{*}{ Religion } & Hindu & 169 & $52(30.7)$ & $117(69.3)$ & \multirow[t]{2}{*}{0.7} & \multirow[t]{2}{*}{$0.4-1.3$} & \multirow[t]{2}{*}{0.2} \\
\hline & Non Hindu & 59 & $23(39.0)$ & $36(61.0)$ & & & \\
\hline \multirow[t]{2}{*}{ Locality } & Urban & 140 & $46(32.8)$ & $94(67.2)$ & \multirow[t]{2}{*}{1.0} & \multirow[t]{2}{*}{$0.5-1.8$} & \multirow[t]{2}{*}{0.9} \\
\hline & Rural & 88 & $29(33.0)$ & $59(67.0)$ & & & \\
\hline \multirow[t]{2}{*}{ Education } & Up to High school & 153 & $48(31.3)$ & $105(68.7)$ & \multirow[t]{2}{*}{0.8} & \multirow[t]{2}{*}{$0.4-1.5$} & \multirow[t]{2}{*}{0.5} \\
\hline & $\begin{array}{l}\text { High school \& } \\
\text { above }\end{array}$ & 75 & $27(36.0)$ & $48(64)$ & & & \\
\hline \multirow[t]{2}{*}{ Occupation } & $\begin{array}{l}\text { Heavy \& } \\
\text { moderate }\end{array}$ & 95 & $34(35.8)$ & $61(64.2)$ & \multirow[t]{2}{*}{0.8} & \multirow[t]{2}{*}{$0.4-1.4$} & \multirow[t]{2}{*}{0.4} \\
\hline & Sedentary & 133 & $41(30.8)$ & $92(69.2)$ & & & \\
\hline \multirow[t]{2}{*}{ SES } & Class 1-3 & 196 & $64(32.6)$ & $132(67.4)$ & \multirow[t]{2}{*}{0.9} & \multirow[t]{2}{*}{$0.4-2.3$} & \multirow[t]{2}{*}{0.8} \\
\hline & Class 4-5 & 32 & $11(34.3)$ & $21(65.7)$ & & & \\
\hline Type of & Nuclear & 127 & $47(37.0)$ & $80(63.0)$ & 1.1 & $0.5-2.5$ & 0.08 \\
\hline Family & Non-Nuclear & 101 & $28(27.7)$ & $73(72.3)$ & & & \\
\hline Family & Present & 114 & $46(40.3)$ & $68(59.7)$ & 1.9 & $1.1-3.4$ & 0.01 \\
\hline h/o obesity & Absent & 114 & $29(25.4)$ & $85(74.6)$ & & & \\
\hline h/o Alcohol & Present & 78 & $33(42.3)$ & $45(57.7)$ & 1.8 & $1.0-3.3$ & 0.02 \\
\hline intake & Absent & 150 & $42(28.0)$ & $108(72.0)$ & & & \\
\hline Smoking & Present & 53 & $20(37.7)$ & $33(62.3)$ & 0.8 & $0.4-1.3$ & 0.4 \\
\hline & Absent & 175 & $55(31.4)$ & $120(68.6)$ & & & \\
\hline Co morbidity & $\geq 2$ & 91 & $42(46.1)$ & $49(53.9)$ & 2.7 & $1.5-4.7$ & 0.0005 \\
\hline & $<2$ & 137 & $33(24.0)$ & 104(76.0) & & & \\
\hline
\end{tabular}

There was no statistically significant association observed between combined obesity and type of the diet $(\mathrm{p}=0.5)$ and physical exercise practices $(\mathrm{p}=0.4)($ Table 4$)$.

Table 4: Association between dietary habits, physical exercise with co-morbid obesity

\begin{tabular}{|c|c|c|c|c|c|c|c|}
\hline \multirow{2}{*}{\multicolumn{2}{|c|}{ Variable }} & \multirow{2}{*}{$\begin{array}{c}\text { Subjects } \\
(n=228)\end{array}$} & \multicolumn{2}{|c|}{ Combined Obesity } & \multirow[t]{2}{*}{ OR } & \multirow[t]{2}{*}{$95 \% \mathrm{CI}$} & \multirow{2}{*}{$\begin{array}{c}\mathbf{P} \\
\text { value }\end{array}$} \\
\hline & & & Yes & No & & & \\
\hline \multirow{2}{*}{$\begin{array}{l}\text { Type of } \\
\text { diet }\end{array}$} & Vegetarian & 58 & $21(36.2)$ & $37(63.8)$ & \multirow[t]{2}{*}{1.1} & \multirow[t]{2}{*}{$0.6-2.3$} & \multirow[t]{2}{*}{0.5} \\
\hline & Non Vegetarian & 170 & $54(31.7)$ & $116(68.3)$ & & & \\
\hline \multirow{2}{*}{$\begin{array}{l}\text { Physical } \\
\text { exercise }\end{array}$} & Yes & 62 & $18(29.0)$ & $44(71.0)$ & \multirow[t]{2}{*}{0.8} & \multirow[t]{2}{*}{$0.4-1.5$} & \multirow[t]{2}{*}{0.4} \\
\hline & No & 166 & $57(34.3)$ & $109(65.7)$ & & & \\
\hline
\end{tabular}

The type of co-morbidities has shown that there was a statistically significant association between combined obesity and subjects suffering from both hypertension and type 2 diabetes mellitus, with proportion of combined obesity higher in subjects with both hypertension and diabetes mellitus (32.4\%) compared with subjects not having both the disorders $(21 \%)$, implying subjects with combined obesity were four times higher risk for hypertension and type 2 diabetes mellitus compared to those without combined obesity $(\mathrm{OR}=3.9, \mathrm{p}=0.001)$. There was no statistically significant association of combined obesity with subjects with only hypertension, only type 2 diabetes, coronary heart disease, gastro entireties, anemia, dengue and bronchial asthma (Table 5). 
Table 5: Association of co-morbidities with combined obesity

\begin{tabular}{|c|c|c|c|c|c|c|c|}
\hline \multicolumn{2}{|l|}{ Variable } & \multirow{2}{*}{$\begin{array}{c}\text { Subject } \\
13\end{array}$} & \multicolumn{2}{|c|}{ Combined Obesity } & \multirow{3}{*}{\begin{tabular}{|c|} 
OR \\
2.4
\end{tabular}} & \multirow{3}{*}{$\begin{array}{l}95 \% \mathrm{CI} \\
0.73-7.7\end{array}$} & \multirow{3}{*}{$\begin{array}{c}\text { P-value } \\
0.1\end{array}$} \\
\hline \multirow{2}{*}{$\begin{array}{l}\text { Hypertension only } \\
\text { (without DM) }\end{array}$} & Yes & & $\begin{array}{c}\text { Yes } \\
6(46.1)\end{array}$ & $\begin{array}{c}\text { No } \\
7(53.9)\end{array}$ & & & \\
\hline & No & 215 & $56(26.0)$ & $159(74.0)$ & & & \\
\hline \multirow[t]{2}{*}{ Diabetes (without HTN) } & Yes & 38 & $7(18.4)$ & $31(81.6)$ & \multirow[t]{2}{*}{0.6} & \multirow[t]{2}{*}{$0.21-1.2$} & \multirow[t]{2}{*}{0.2} \\
\hline & No & 190 & $55(29.0)$ & $135(71.0)$ & & & \\
\hline \multirow[t]{2}{*}{ HTN and DM } & Yes & 47 & $24(32.4)$ & $23(67.6)$ & \multirow[t]{2}{*}{3.9} & \multirow[t]{2}{*}{$1.9-7.7$} & \multirow[t]{2}{*}{0.001} \\
\hline & No & 181 & $38(21.0)$ & $143(79.0)$ & & & \\
\hline \multirow[t]{2}{*}{ Coronary heart disease } & Yes & 18 & $4(22.2)$ & $14(77.8)$ & \multirow[t]{2}{*}{0.7} & \multirow[t]{2}{*}{$0.2-2.2$} & \multirow[t]{2}{*}{$0.8^{\#}$} \\
\hline & No & 210 & $58(31.0)$ & $152(69.0)$ & & & \\
\hline \multirow[t]{2}{*}{ Gastro-entireties } & Yes & 27 & $10(37.0)$ & $17(63.0)$ & \multirow[t]{2}{*}{1.7} & \multirow[t]{2}{*}{$0.6-3.9$} & \multirow[t]{2}{*}{0.2} \\
\hline & No & 201 & $52(25.8)$ & $149(74.2)$ & & & \\
\hline \multirow[t]{2}{*}{ Anemia } & Yes & 22 & $5(22.7)$ & $17(77.3)$ & \multirow[t]{2}{*}{0.8} & \multirow[t]{2}{*}{$0.2-2.1$} & \multirow[t]{2}{*}{0.6} \\
\hline & No & 206 & $57(27.7)$ & $149(72.3)$ & & & \\
\hline \multirow[t]{2}{*}{ Dengue } & Yes & 28 & $8(28.5)$ & $20(71.5)$ & \multirow[t]{2}{*}{1.1} & \multirow[t]{2}{*}{$0.4-2.6$} & \multirow[t]{2}{*}{0.9} \\
\hline & No & 200 & $54(27.0)$ & $146(73.0)$ & & & \\
\hline \multirow[t]{2}{*}{ Bronchial asthma } & Yes & 12 & $03(25.0)$ & $09(75.0)$ & \multirow[t]{2}{*}{0.9} & \multirow[t]{2}{*}{$0.1-3.6$} & $0.9^{\#}$ \\
\hline & No & 216 & $59(27.3)$ & $157(72.7)$ & & & \\
\hline
\end{tabular}

\section{\#Yates Chi Square}

\section{Discussion}

The primary results of the study indicated that around one third $(32.9 \%)$ of the study subjects had combined obesity. Similar observation was made by Zhang $\mathrm{M}$ et al in China shown that $32.5 \%$ of the subjects had combined obesity. ${ }^{9}$ Contrary to these finding, ICMR - INDIAB - 3 study observed that burden of combined obesity was $26.6 \%, 19.3 \%, 13 \%$ and $9.8 \%$ respectively in Chandīgarh, Tamil nadu, Maharashtra and Jharkhand. ${ }^{7}$ The disagreement between these results could be due to differences in set up, study design, geography, socio-economic and sociocultural background of the subjects.

In the present study, proportion of combined obesity was high among males compare to females. Similarly, in a study conducted by Hou $\mathrm{X}$ et al has found that both BMI and WC were high among males compared to females. ${ }^{10}$ Contrary to these findings, a study found that combined obesity is high among females compare to males. ${ }^{7}$ These evidences support that combined use of BMI and WC as a better index to differentiate obesity based on sex because BMI alone cannot differentiate total body fat mass according to sex as a major limitation.

This study recorded $24 \%$ of the subjects were found to have high central obesity among normal and below normal BMI category. This finding clearly shows that $24 \%$ of the centrally obese subjects will be missed if BMI alone is considered, because Asian Indians have greater predisposition to central obesity and accumulation of visceral fat. These findings were supported and strengthened by studies conducted elsewhere. ${ }^{11-12}$ These findings indicate that abdominal obesity varies dramatically with in the narrow range of BMI categories and these evidences confirm that combination of BMI and WC are practical measure of obesity.

The combined obesity is associated with family history of obesity and history of alcohol intake. Hence, these factors can be used as a tool of screening to detect adults at-risk of developing obesity. Subsequently, further probe is needed to find out the influence of these factors on combined obesity.

In the current study, combined obesity is associated with presence of two or more co-morbidities. This finding is consistent with study conducted by Cho YG on Korean adults, where combination of BMI and WC predicted high obesity related co-morbidities. ${ }^{13}$ These observations add to the growing body of evidence that WC provides additional information on risk of comorbidities when used along with BMI.

In this study, combined obesity is associated with both hypertension and type 2 diabetes mellitus. Similarly, many studies on Asians observed that hypertension was strongly associated with BMI and Type 2 diabetes mellitus with WC because WC reflects abdominal obesity which is closely associated with impaired glucose metabolism and BMI reflects body fluid volume which is closely associated with hypertension, therefore both indexes in combination is considered as superior and improves the predictive power of finding cardio-metabolic and cardio-vascular diseases. All these facts appreciate the utility of combined obesity based on BMI and WC. ${ }^{10,14}$

\section{Conclusion}

In this study, $32.9 \%$ of the study subjects had combined obesity and associated with family history of obesity, history of alcohol intake, presence of two or more co-morbidities and hypertension with type 2 
diabetes mellitus. The combined obesity based on BMI and WC is a better index of obesity.

Limitations: The current study is limited by crosssectional nature of study design and included only inpatients from medical wards.

Recommendations: This study appreciate the utility of combined obesity based on BMI and WC in hospital set-up and recommends that there is a need for such studies in hospital and population settings to find out the extent of the problem, cut-off values and associated risk factors for formulating prevention and control programme against combined obesity, which definitely help in reducing morbidity, premature mortality and health care cost related to obesity among Indian adults in future.

Financial Support: None declared

Conflict of Interest: None declared

\section{References}

1. Chauhan RC, Chauhan NS, Manikandan, Purty AJ, Mishra AK, Singh Z. Obesity among adult population of a rural coastal area in South India. Int J Sci Rep 2015;1(3):155-8.

2. Nuertey, Benjamin D. et al. Prevalence of obesity and overweight and its associated factors among registered pensioners in Ghana; a cross sectional studies. BMC obesity 2017;4:26.

3. Kulie T, Slattengren A, Redmer J, Counts H, Eglash A, Schrager S. Obesity and women's health: An evidencebased review. J Am Board Fam Med 2011;24:75- 85.

4. Ramya. MR, Seetharaman N, Lokeshmaran A, Hema Priya S. Prevalence of obesity in rural and urban areas of Puducherry and comparison of its correlates and comorbidities among obese and non-Obese Individuals. Int J Health Sci Res 2017;7(11):1-8.

5. Gierach M, Gierach J, Ewertowska M, Arndt A, Junik R Correlation between body mass index and waist circumference in patients with metabolic syndrome. ISRN Endocrinology 2014;1-6.

6. Behla S, Misra A. Management of obesity in adult Asian Indians. Indian Heart Journal 2017;69:539-544.

7. Pradeepa R, Anjana RM, Joshi SR, Bhansali A, Deepa M, Joshi PP, et al. Prevalence of generalized \& abdominal obesity in urban \& rural India- the ICMR-INDIAB study (phase-I) [ICMR-INDIAB-3]. Indian J Med Res 2015;142:139-150.

8. Sanjay TV, Arun Kumar DP, Madhusudan M. Prevalence and determinants of obesity among elderly in an urban area of Bengaluru. NJCM 2017;8(11):672-677.

9. Zhang M, Zhao Y, Wang G, Zhang H, Ren Y, Wang B et al. Body mass index and waist circumference combined predicts obesity-related hypertension better than either alone in a rural Chinese population. Sci Rep 2016;6:31395.

10. Hou X, Lu J, Weng J, Ji L, Shan Z, Liu J et al. Impact of waist circumference and body mass index on risk of cardiometabolic disorder and cardiovascular disease in Chinese adults: A national diabetes and metabolic disorders survey. PLoS ONE 2013;8(3):e57319.
11. Song-Ming DU, Ma GS, Li YP, Fang HY, Hu XO, Yang $\mathrm{XG}$ et al. Relationship of Body Mass Index, Waist Circumference and Cardiovascular Risk Factors in Chinese Adult. Biomedical and Environmental Sciences 2010;23:92-101.

12. Højgaard B, Gyrd-Hansen D, Olsen KR, Søgaard J, Sørensen TIA et al. Waist circumference and body mass index as predictors of health care costs. PLoS ONE 2008;3(7):e2619.

13. Cho YG. Cardiovascular risk assessment based on combined body mass index and waist circumference in Korean adults. Korean J Fam Med 2017;38:313-314.

14. Feng RN, Zhao C, Wang C, Niu YC, Li K, Guo FC et al. $\mathrm{BMI}$ is strongly associated with hypertension, and waist circumference is strongly associated with type 2 diabetes and dyslipidemia, in northern Chinese adults. J Epidemiol 2012;22:317-23. 